\title{
Classroom Research in Large Cohorts: An Innovative Approach Based on Questionnaires and Scholarship of Teaching and Learning on Multiple-Intelligences
}

\author{
Siva PR Muppala ${ }^{1} \&$ Balasubramanyam Chandramohan ${ }^{2}$ \\ ${ }^{1}$ School of Engineering and the Environment, Kingston University London, United Kingdom \\ ${ }^{2}$ Institute of Commonwealth Studies, School of Advanced Study, University of London, United Kingdom \\ Correspondence: Siva PR Muppala, School of Engineering and the Environment, Kingston University London, \\ Friars Avenue, Roehampton Vale, London, SW15 3DW, United Kingdom. E-mail: s.muppala@kingston.ac.uk
}

\author{
Received: April 15, 2020 Accepted: May 16, 2020 Online Published: May 28, 2020 \\ doi:10.5539/jel.v9n3p106 URL: https://doi.org/10.5539/jel.v9n3p106
}

\begin{abstract}
In this work we focussed on assessment and quantification of students' prior knowledge at the start of their classes and the learning and teaching feedback given by them after their classes. Using questionnaires, we collected data on prior-knowledge/Student Learning Abilities - SLAs and, students' performance/Learning Outcomes - LOs. Our analysis shows that typically, in any classroom the SLAs follow a non-linear trend. This pattern, identified in group learning, requires proportionally distributed intervention by staff, with more support to those in need of help with learning. We show that the above approach, underpinned by an application of Multiple Intelligences and e-learning facilities, supports weaker students and helps them to achieve higher pass percentages and better LOs. This innovation in terms of evidence-based identification of need for support and selective intervention helps in optimal use of staff time and effort as compared to a one-method-fits all approach to learner development and academic achievement.
\end{abstract}

Keywords: formative assessment, quantification of learning, multiple-intelligences, Scholarship of Teaching and Learning (SoTL)

\section{Introduction}

Classroom inquiry is one of the multi-faceted Scholarship of Learning and Teaching (SoTL) approaches. McCarthy (2010) praises the work of Hutchings (2004) and concludes in her review that teaching is an intellectual work and student learning in large classes poses unique problems. She terms this investigation of problem solving under "classroom activities" (Brew, 2012). A plausible solution, suggested in this paper is research-based formative assessments, which have been in place for over twenty years in Europe. However, the UK universities still see research and teaching as two separate entities in the context of research assessment systems (Cabral \& Huet, 2011). We see good prospects in handling rich mixture of students with various learning abilities using local research results. It is a new dimension to learning -- with focus on helping weaker students through quantitative assessment. This subject has not been looked into before.

Assessing learning should be inclusive of academic research findings in classroom. These assessment results paves way for improving students' learning and on reflection provide a platform for equalising studies in a large class cohort. In a recent work, Rotgans (2018) proposed a student's model to articulate the team-based learning. In the handbook edited by Bryan and Clegg (2019), in chapter 1, King (2019) notes post-1992, a range of innovative formative assessments is a necessity, a manifestation of The UK Quality Code (2018) -- because higher education landscape is vastly different. King also emphasises there is a good correlation between group learning, pedagogic value and assessment practice. So, in this study we demonstrate the value of coherent, consistent and collaborative approaches to assessment for learning.

\section{Scholarship of Learning and Teaching}

The UK government is heavily investing in the scholarship of learning and teaching. This study partly addresses this attempt at balancing of teaching and research activities. Using questionnaires and formative assessments, we attempt to show coherence between them. With the evidence collected, we argue that there is a general 
relationship between informal collaborative learning with learning output, achievement of learning satisfaction and pass percentage. Learning is a derived value based not only on the complexity of the content but also on the prior knowledge of the learner. The present authors define the classroom as the knowledge of the field. The learning question is how SoTL can help improve learning outcomes for students. Cerbin (2013) also inquires this research question, what or how much did students learn? McCarthy analogizes the SoTL as bringing the virtually 'dead' problem to active learning (Jaques, 2001). In this context, an issue that is addressed is why/how teaching AND research are differentiated rather than being integrated. McCarthy argues that research is given a back seat in comparison to teaching. She views that research has more advantages and benefits students' learning and academic's delivery. Thus, she supports the views of several authors that identify time for one's own research is drawn from teaching.

Hutchings (2013) questions if there is any general consensus if SoTL is discipline specific or could it be applied independent of discipline. He goes on to say that with a few necessary changes, so-called, universal models could be applied to some specific courses. In line with this view, we have made an effort to interpret students learning in purview of SoTL. For this, we use questionnaires for formative assessment (first-year module Level-4, second-year module Level-5 and Master's module Level-7) and the final module feedback (Level-5). The expectations for quality in all these modules are that the students are reliably assessed and provided support to succeed in and benefit from higher education, especially the weaker students, The UK Quality Code (2018). Whilst the students with other different levels of skills/competences get more benefit from an environment conducive to learning. Our current goal here, particular to engineering disciplines, is to validate students' learning achievable by measuring the learning of a rich mixture of students. This paves way for development of an education mode that is presented and discussed at the end of this paper. This method leads to quantification of learning of a rich mixture of students and for this an education model is presented.

\subsection{Students of Varied Learning Abilities (or Levels?)}

First, students with varied levels of competencies are admitted to the university based on a spectrum of pre-entry qualifications, and second, different abstraction levels of students, such as mathematical skills. Data collection is used here to categorize them based on their skills/abilities. This helps the tutor to tune lecturing methodologies to improve the students' learning satisfaction and their final marks. Therefore, as part of this classroom testing procedure, a standard set of combination of simple and complex tasks are prepared and given to the students to answer. The data are analysed.

With advent of technology, current research in L/T puts strong emphasis on digitalization. Use of digital resources helps students' satisfaction as well as their learning. It paves way to encourage students from minority communities to take leadership. Digitalization helps blended learning, and can theoretically handle any class size and helps transfer their skills to work place. We use simple techniques as a part of the formative assessment, by routinely posting questions online to enhance students' interest and keep them attentive throughout as many interactive sessions as possible by giving a set of exercise problems, with a short briefing, to complete the task in a stipulated time. This provides them with a short revision of the related concepts in the lecture (Love, Hodge, Grandgenett, \& Swift, 2014).

This paper builds on the idea that one-size does not fit-all (Dirksen, 2016) and presents analysis of data to pre-assess their knowledge through formative assessments based on three questionnaires. We try to construct an evidence-based approach. We have gathered the data in three different modules in different years. From this, we draw some innovative ideas that may help other academics in the classroom activities in different disciplines. In particular, students with comprehension difficulties and maths support require an extraordinary devotion (this requires devising class groups, setting up additional sessions, and additional time from academics etc.) to help weaker students on individual basis. This is discussed further with formative assessment test, support offered and its potential impact on module LOs.

For all assessments below, we set the questions in three types, simple, moderately difficult and difficult questions. This classification helps differentiate among, more able, moderate level and weaker students.

In this study, we exercise our discussions based on what was gathered in the form of feedback/formative assessment and our main findings are presented in comprehensive bar charts.

\subsection{Significance of This Study}

In the wider UK higher education sector, there is a change in the funding policy to enable more recruitment through widening participation. Kingston university, where this study is based, has received UK Social Mobility Awards 2019 for championing fair access and inclusivity in higher education. The university attracts students 
from more than 60 different countries, providing opportunities to reach their potential (Newman \& Knight, 2018).

\section{Review of Measurement of Learning}

Clark and Webster (2012) argues, by definition, innovation and creativity are two different elements. Plsek (1999) suggests 'creativity is the connecting and rearranging knowledge...'. The novelty in this study is we use an innovative multi-dimensional approach with more than one educational strategy: problem-based learning laced with multiple intelligences, formative assessment in group learning, and use of three questionnaires. The group learning is based on formative tests to encourage cooperation and not competition (González-Marcos, Alba-Elías, Navaridas-Nalda, \& Ordieres-Meréc, 2016). We are aware competition in classroom means development of fear, and fear stops intelligence. Prince (2004) in a review article evidences that cooperative learning builds stronger, permanent, and expanding problem-solving skills. Matrisciano and Belfore (2010) experimentally identify the learning differences in two different student groups based on Cognitive styles theories. They say their results have been useful to the students that can receive help on their personalized learning. Fuller, Kuhne and Grey (2011) define four categories of courses where engineering disciplines fall predominantly into Analysis/Synthesis courses. These courses teach students to analyse and articulate a problem (Fuller \& Kuhne, 2008). A numerical Thermodynamics problem of a piston-cylinder assembly is given in Appendix A and its findings in Figure 1. The learning of such a problem classifies the students' abilities (see Figure 1). This knowledge of classification has paved way for more interdisciplinary programmes in the university sector; for example, Kingston university has students from $\sim 140$ countries, with a wide spectrum of abilities and interests. Therefore, the focus of teaching in engineering subjects is shifting from subject(s) itself to problem-based learning (PBL). PBL is a mixed instructional approach with self-directed learning, which has a better fit for more able students; and, group learning, that benefits middle-level to some extent and weaker students thoroughly (Prince, 2004). He cites the work of Law et al. (1999) in which the method of pause in active learning increases the longer retention of lecture material. This is a form of PBL. PBL in group learning in engineering disciplines is more effective and we discuss it in modelling approach perspective below. Therefore, we think it is necessary to understand the learning quantitatively. This can be achieved by analytically estimating the levels of learning achievements by students working independently or in smaller groups, of maxim group size, typical of five for cooperative learning (Muppala \& Chandramohan, 2017). The succession of this study paves way for the development of a numerical model to quantify learning through PBL approach (Muppala \& Chandramohan, 2017). We hope it helps the weaker students to perform relatively better on the critical-thinking tests on par with the students who are relatively more studious.

\section{Theoretical Modelling}

Many different teaching strategies enhance learning outcomes (LOs) (Gardner, 2006). It not only brings good LOs, but also brings a positive effect on learning (Cerbin, 2013). Gardner (2006) coined the term intelligences - a scientific tool to quantify success/failure. Many suggestions have been made on how to use intelligences and its varied applications. He cites Jensen, a psychologist, who suggests a sequence of events with reaction time as a parameter to assess intelligence. This can be likened to an assessment, either formative or summative, of students' learning in a classroom. Gardner proposes a one-dimensional view - which he calls 'uniform view'. This is primarily -- a curriculum, which in educational terms simply means -- learning objectives and learning outcomes that all students should know and achieve. He further adds that assessment is a widely accepted measurement, and that problem-solving skill is routed through the intelligences.

MIs gain significance when the students' learning skills are diverse and its application can be extended to group learning. In a group learning/flipped classroom, the instructor's role is minimal, but s/he is readily available to answer any questions or to throw new thoughts or ideas into the discussions. This technique is found to be quite effective with respect to the students.

For assessments, we set the questions in three types:

a) Questions asked by questions

b) Simple questions

c) A small set of difficult questions. This section differentiates between deep learners and surface learners (middle and weaker) students. 


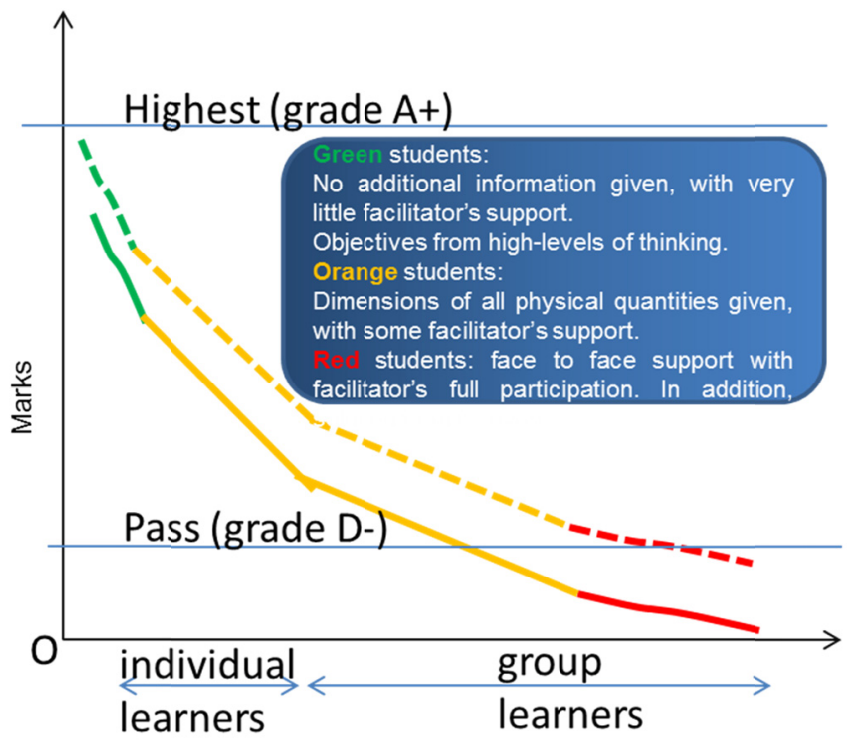

Figure 1. An empirical model from first author's classroom experience showing division of students learning abilities in three categories (Muppala \& Chandramohan, 2019)

It shows a comparison of student grouping against marks. The grouping is based on their learning/abilities. From a philosophical perspective any division leads to conflict. However, for practical purposes, our teaching experience shows that such a virtual division gives flexibility to value and supports the development of students' skills.

Figure 1 shows a curvilinear trend depicting three categories, based on their learning abilities/skills (Muppala \& Chandramohan, 2019; Algozzine, 2007). Sub-divisions are further possible, based on the entry level qualifications, Black, Asian and Minority Ethnic (BAME) students, gender etc.

Figure 1 shows the students in the red need constant support or intervention from instructor. There is no clear-cut interface between the divisions and there is expected to be an overlap. These are devised from the first author's teaching experience. Red-level represents weaker students who need extensive support inside classroom or outside; Orange level represents average students, and Green-level represents able/creamy students. Bold and dashed lines indicate before and after tutor's support. Close observation of the hyperbolic trends shows the difference between green lines in thinner at the start and gradually grow relatively bigger in the red region. Here, Green represents those students who tend to achieve highest grades, Orange indicates students who need marginal support to achieve LOs, and the weaker/weakest are those ones shown in Red. This last category of students' is of particular interest as it poses a challenge to an educator. It is a challenge because, the educator must engage as an 'external invention' to facilitate all students in group to discuss and interact (Fuller, Kuhne, \& Frey, 2011, p. 21).

Therefore, here tutor's intervention is seen as a norm, and these students need constant one-to-one support, either in flipped classroom or online, in the case of Kingston University via Canvas, the VLE used in the University.

We elaborate this in Figure 1 with an engineering problem. Typically, any engineering course falls into the category analysis/synthesis courses (Fuller, Kuhne, \& Frey, 2011). Therefore, a stepwise solution is attempted. Analysis/synthesis course teaches students to solve a problem by questioning creatively (Fuller \& Kuhne, 2008).

Multiple Intelligences (MI) is a pluralized traditional concept, it is merely a ritual exercise that a solution can be achieved irrespective of the age, training or prior knowledge. The original set of intelligences is: Musical, bodily-kinesthetic, logical-mathematical, linguistic, spatial, interpersonal, intrapersonal and some newly identified intelligences.

We interpret this idea cautiously and apply to an engineering problem -- characterization of fluid flow in a pipe - that is split into three stages of learning. Here, the low-level students familiarize themselves up to the level of knowing physical quantities involved i.e., fluid properties (e.g., density and viscosity): flow quantity velocity, and geometrical quantity, pipe diameter and other physical units. To proceed to the next step(s), they 
need instructor's support to get to the problem.

The middle-level students understand the physics of the problem, wherein a non-dimensional quantity the Reynolds number Re is introduced that is a function of all above four physical quantities. It is the ratio of two forces in a flow that characterizes the type of flow. If $\mathrm{Re}$ is $<2400$ the flow is termed laminar and anything $>$ 5500 is turbulent. They can solve numerical problems with little or no support.

Third and final, high-level students who are far ahead of others can handle more complex problems, with varied complexity of fluid flow and different geometrical configurations, such as flow over a cylindrical object. As noted earlier, this class of students is near independent learners that can analyse a situation and engage in problem solving (Fuller \& Kuhne, 2008). The most striking difference is that these higher-order thinking students could interpret and solve a different problem.

In the following description, we outline our proposed theoretical (or pragmatic) model to assess the students' levels/abilities by incorporating more than one educational strategy for assessing how we can help the weaker category of students effectively and efficiently. These are presented in three questionnaires.

\section{A Pragmatic Approach for Handling of Large-Size Class Cohort}

The greatest challenge is lecturing to large-size class cohorts. In an engineering module, a mix of Mechanical \& Automotive and Aerospace students share same classroom. In such a wide diversity, three important factors are interlinked. In order to recognize this, the instructor needs additional support in the form of digitization. Therefore, all UK universities are progressively over years going for e-learning, with the aim to increase:

- students' achievements (pass percentage \& overall satisfaction)

- lecturer's satisfaction (teaching through self-reflection), and

- Course/syllabus completion within the allotted timetable.

In order to provide support outside classroom with an aim to improve LOs, we adopt a four-pronged approach: a) an issue is raised, b) analyzed, c) followed by required intervention and d) reflection. The benefits of the approach are building classroom material and encouraging students to look for e-learning resources.

\section{Questionnaire - 1:}

Choosing the methods of assessment is one of the most critical of all influences on the students' learning (Ramsden, 1992). Here, formative assessment is based on a Thermodynamic mathematical problem that is attempted in 24 small-size groups' involving 64 students, with group size randomly made by students themselves. This distribution (see Figure 2) helps to understand the dynamics of group learning.

Literature provides evidence (Gargiulo, 2016) that supports principles of these methodologies, DI \& universal design of learning accounts for student characteristics and sectionalizes how to overcome barriers to learning. Gargiulo and Metcaf (2016) has significantly contributed to mathematical modelling for developing measurement of learning. Metcalf identifies 'divisional' approach on three components, based on two categories of students: low level and high level. The present authors independently propose a model based on three classes.

The present task requires basic knowledge of

a) Thermodynamics and the ability to understand the problem and identify the given information, data required from thermodynamics charts, necessary formulae and their appropriate usage. Here, the learner is expected to understand how to correctly sketch the thermodynamic processes on the process diagram such as pressure vs. specific volume and to replicate the same on other plots such as temperature vs. specific volume.

b) Application of first law of thermodynamics to new and complicated processes, and appropriate use of the standard sign conventions for heat and work, and to keep the units consistent.

It is an opportunity to engage in the transferability of skills and knowledge gains from classroom in solving the current and any related future problems. Key skills include scientific ability to test the feasibility of any complex thermodynamic system and to be able apply mass and energy balances to such systems. Other important factors that bring recognition in one's professional career include good teamwork, communication and research scientific skills as a result of group work at the academic level (Lei, 2005).

Findings: Figure 2 shows the results from a test based on PBL technique involving sixty-four students who make up 22 groups; of these nine groups produced no work (Lei, 2005). The correlation results for group performance as a function of number of students in a group are shown in Figure 2. Here, the straight line is an ideal fit invariant of the group size. 


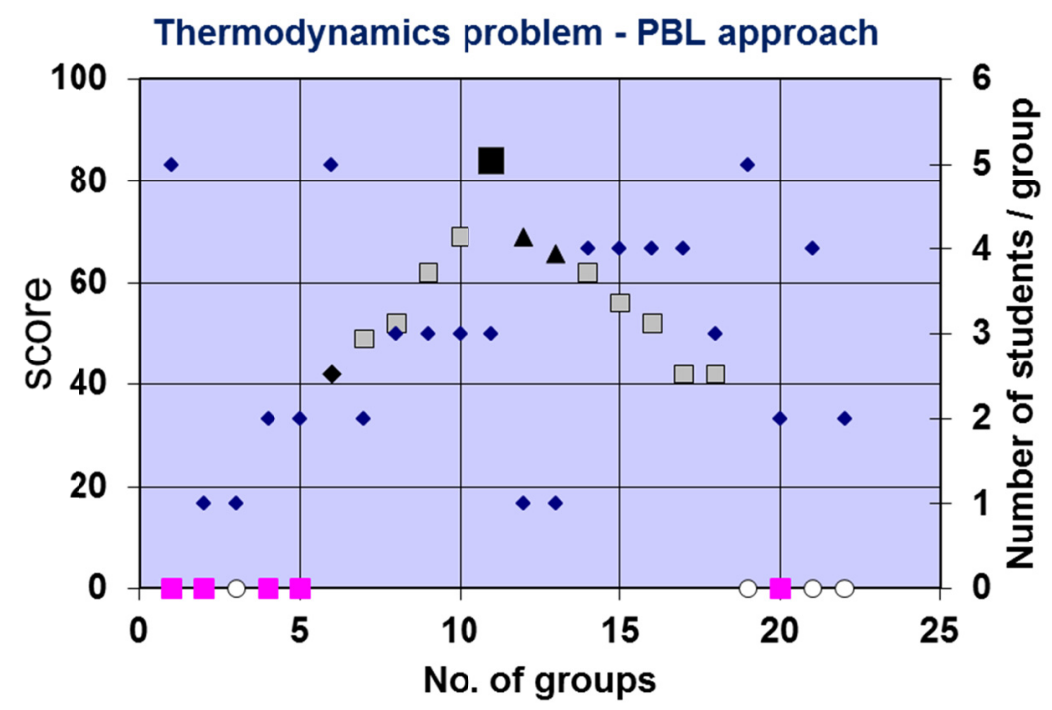

Figure 2. Student performance of the task for the numerical problem, given in Appendix A

Figure 2: Correlation plot depicting the group performance versus number of students per group, number of groups in horizontal axis. Twenty-two groups are involved in which there are four students who are self-directed learners. Therefore, the total number of students assessed is sixty-four. This study infers that smaller groups, as a thumb rule of five yields positive effect on academic achievement whereas any self-directed has the opposite effect (Prince, 2004) citing (Norman \& Schmidt, 2000). This is especially true if the weaker student works on his/her own. Our findings are similar where four students who worked independently were weaker students, couldn't improve his/her solving problems skills in self-directed learning (with marks $<20$ ), compared to majority of group learners. Those with zero marks did not contribute to learning, due to non-participation and/or due to late attendance. It is to be noted that the sub-classification of weaker students -- Black, Asian and Minority Ethnic (BAME), international students etc. is beyond the scope of this study, as data are not currently available.

In further details of Figure 2, these data are analysed for the performance of groups in varied group sizes. (The green thick lines give the best performance of the students, irrespective of the group sizes.) Despite the smaller group size of three, the group with symbol (- ) has performed well with grade A (close to the horizontal green thick line). As shown in the figure, groups of three and four students $(\square)$ have in general attained average results scattered in the range 40 to 70 which are encircled; the fitted curve passing through these points with an average grade $\mathbf{C}$. In most other cases $(\odot)$, irrespective of the group size from two to five students, the groups have failed. However, a clear-cut causal relation cannot be established between group size and performance, based on this set of three inferences. We think this inconsistency of results is attributable to random group sizing. We are aware that availability of additional data can help to undertake more detailed investigations.

Some of the observations from Figure 2:

- Group learning gave the students an opportunity to work on a cooperative basis to analyse, synthesize and evaluate ideas.

- Non-graded assignments help towards collective improvement, and enhance skills of weaker students in heterogeneous grouping. MIs theory helps classify students in group learning and that educator can devote additional time and energy for more needy through face-to-face support, which could facilitate building good rapport between the educator and the students and nurture interest in the subject.

- This investigation shows the dynamics of students' group learning.

- The overall observation is that smaller groups perform better. This idea is further discussed below in a modelling approach.

\section{Multiple-Intelligences (MIs)}

Gardner in Multiple Intelligences: New Horizons (p. 60), focuses on how to reach more students, in three entry points for learning: 
- linguistic or graphical intelligences

- logical mathematical

- through practice.

Gardner suggests that these entry points are enough for individualized education. He says that he sets educational goal of an education X, but had to be content with Y, what student achieves (Gardner, 2006). However, even with disciplinary understanding as stated on page 59 that for basic level (first year) learners it is enough to achieve the educational goal, based on students' absorption levels (Barrington, 2007).

Finding a solution to a numerical problem such as in Figure 2 typically involves a matrix of multiple intelligences:

- The students or groups of students who are thriving educationally are closely related to musical and spatial intelligences

- The solution which is attempted in self-formed varied sizes of groups, requires interpersonal and intrapersonal intelligences

- However, for a mathematics-based problem, of all seven MIs the closest one is logical-mathematical intelligence. So, the solving abilities of the students are streamlined with this intelligence. All students are assessed with the same problem (but at varied levels) to show the different intellectual profiles of students: We use this information to craft the optimal education for each learner.

\section{Questionnaire - 2:}

This questionnaire contains 19 questions. Responses were collected on the last contact session of the second-year Fluid Mechanics (FM) module (Lock, 2007). The questions are listed elsewhere (See Muppala \& Chandramohan, 2019), to avoid similarity of text. It was answered by a third of the 42 students registered in the academic year 2018/19. The students' anonymous responses are plotted on bar charts and mapped with multiple-intelligences.

These are then classified into four themes:

- $\quad$ Fluid Mechanics (FM)

- Teaching and Learning

- Communication

- Tests/exams

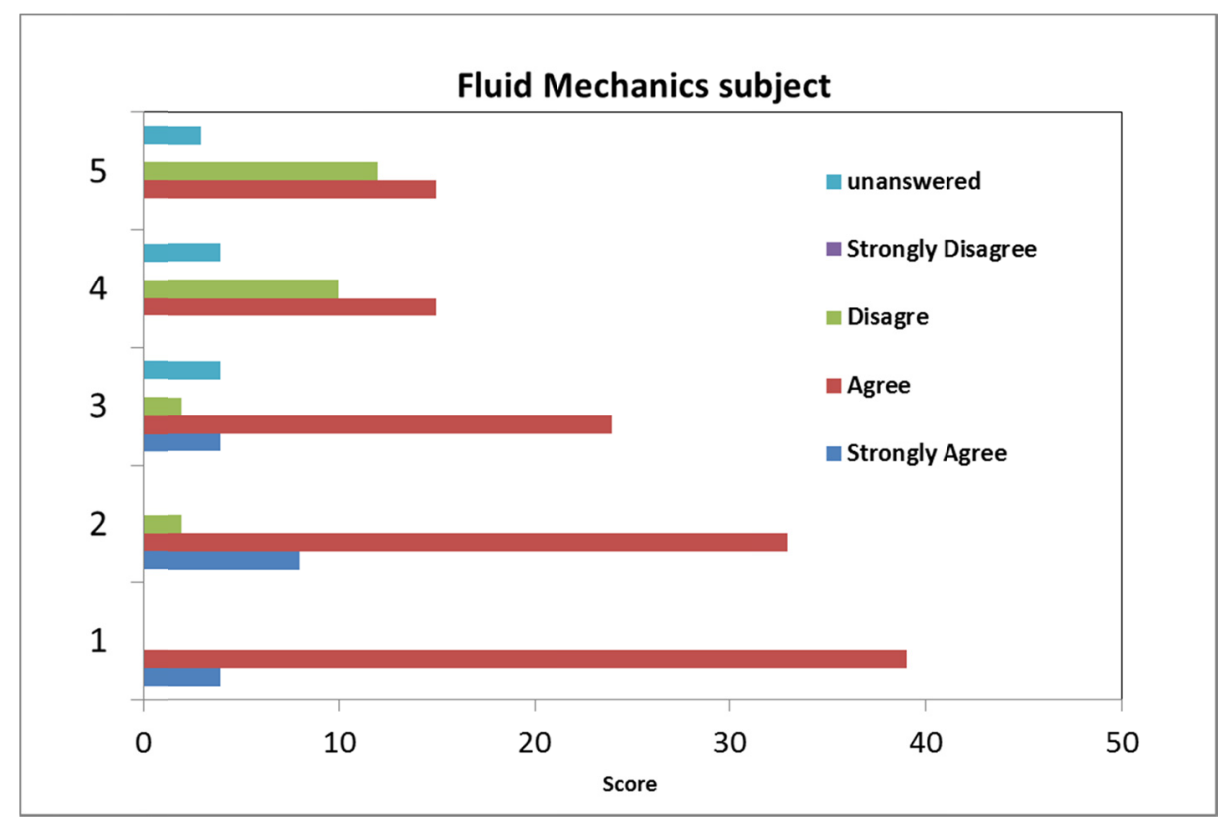

Figure 3a. Students' responses to five questions on the subject

(x-axis shows respondents and y-axis the question number, in all Figures $3 \mathrm{a}$ to $3 \mathrm{~d}$ ) 
The data are not tabulated to avoid repetition. The scoring is given for Strongly Agree, Agree, Disagree and Strongly disagree, with score scale of 4 to 1 , respectively.

This subject requires logical-mathematical, and spatial intelligences. A detailed consideration of both intelligences conveys an engineer solving a real-time system. It often requires sensible assumptions to be made and use of proper constants with correct decimals, for e.g., use of pi-value 3.14 or 3.147 depending on the needs of the design. Therefore, an engineering student should identify the required gas constants, based on the units of physical quantities (a classroom numerical problem is given in Appendix A). In reality, for example environment engineer needs to have knowledge of weather data filter techniques and skills for interpretation of analytical profiles of clouds.

Overall, the bar chart Figure 3a shows in all subject related questions, at the end of the module the students consider themselves capacitated with subject learning. This is a good achievement for the academics involved in designing and delivering subject content of the module/course.

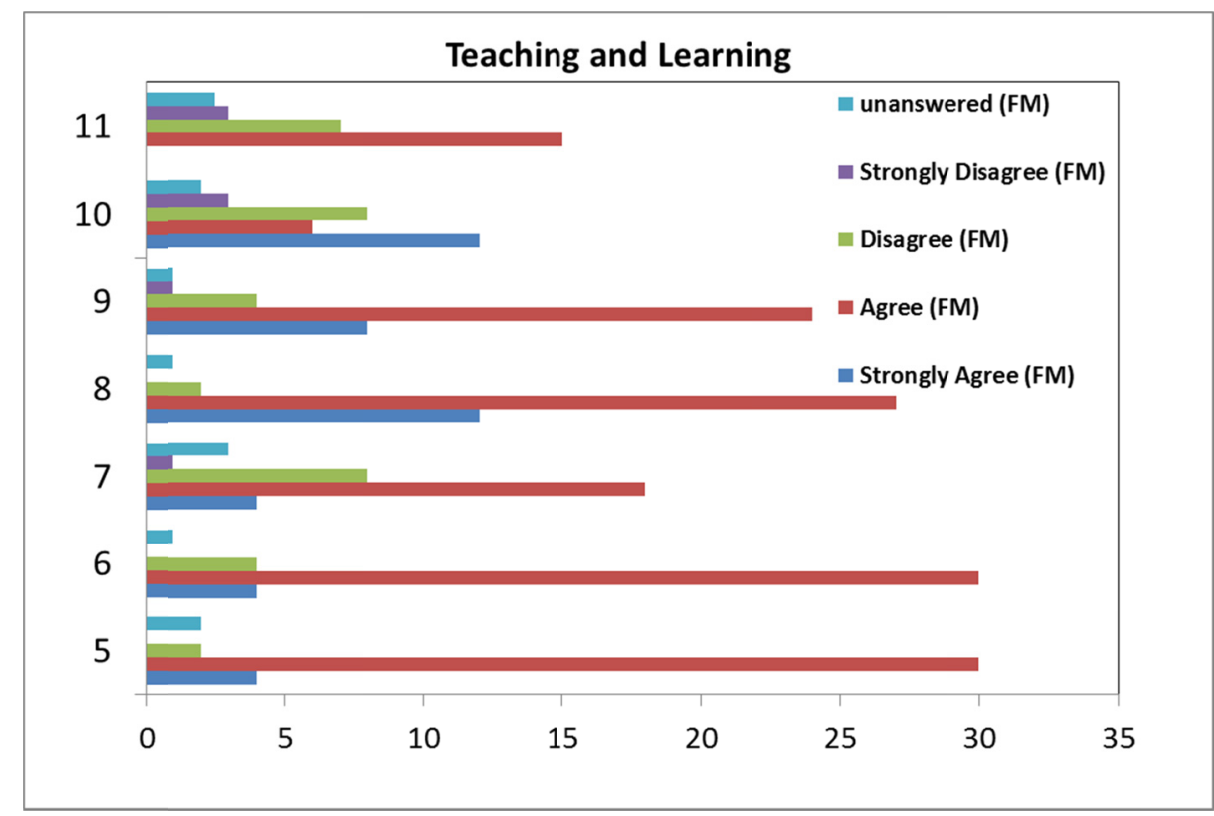

Figure $3 b$. Students' responses on four questions on teaching and learning

This element shown in Figure $3 b$ is mostly to do with self-preparation. This requires regular and consistent reading, which primarily helps weaker students as the material is accessible on Kingston University's VLE platform, Canvas, from anywhere and anytime. Rigorous practice helps to improve thought processes. For providing responses to these questions, students need three MIs: local-intelligence (solving problems), linguistic (for write up and communication with fellow group mates and instructor) and spatial (browsing Canvas for lecture material, assignments and conference chats). Overall, the students have given high scores for Teaching and Learning, which indicates that the facilitation of learning in the Module has successfully leveraged relevant MIs. 


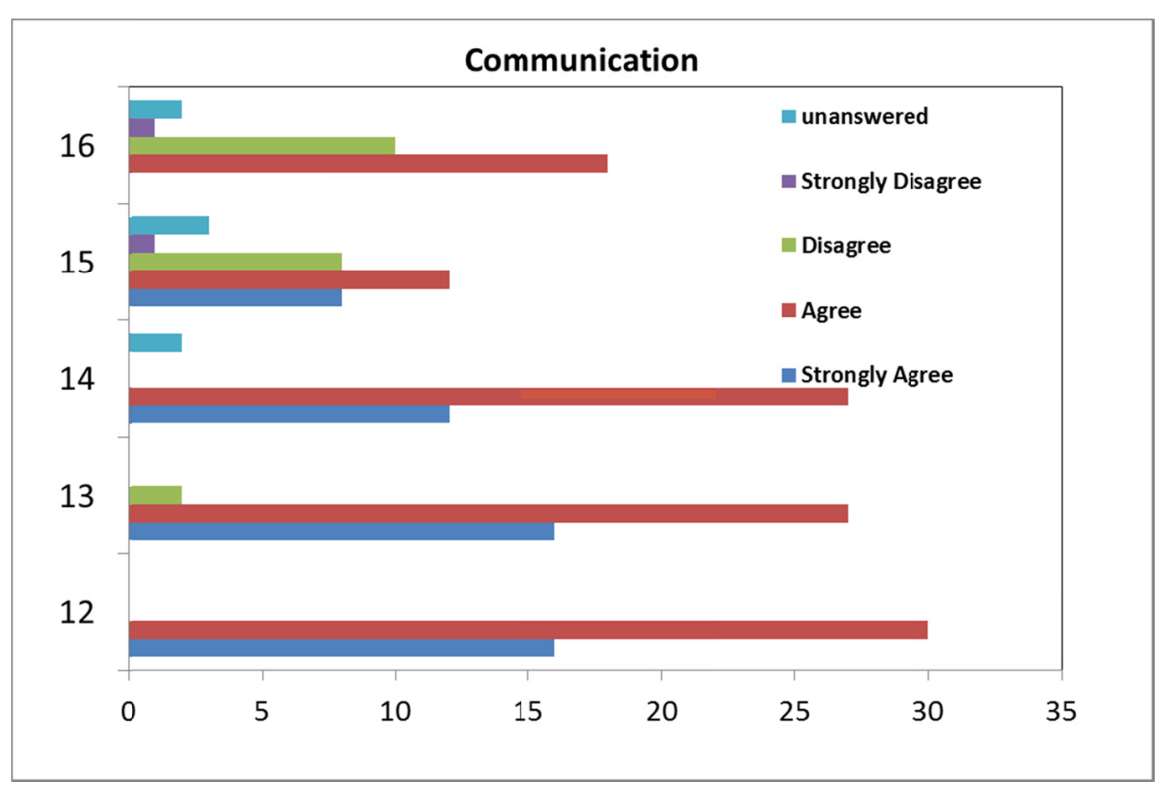

Figure 3c. Students' responses on four questions on communication

Again, here in Figure 3c, in addition to spatial-and-linguistic, good interpersonal and intrapersonal skills are needed for formal learning. Despite several facilities, it is still seen as an exhausting approach to actively engage students, in the Kingston University's official online platform Canvas, especially in e-formative assessments.

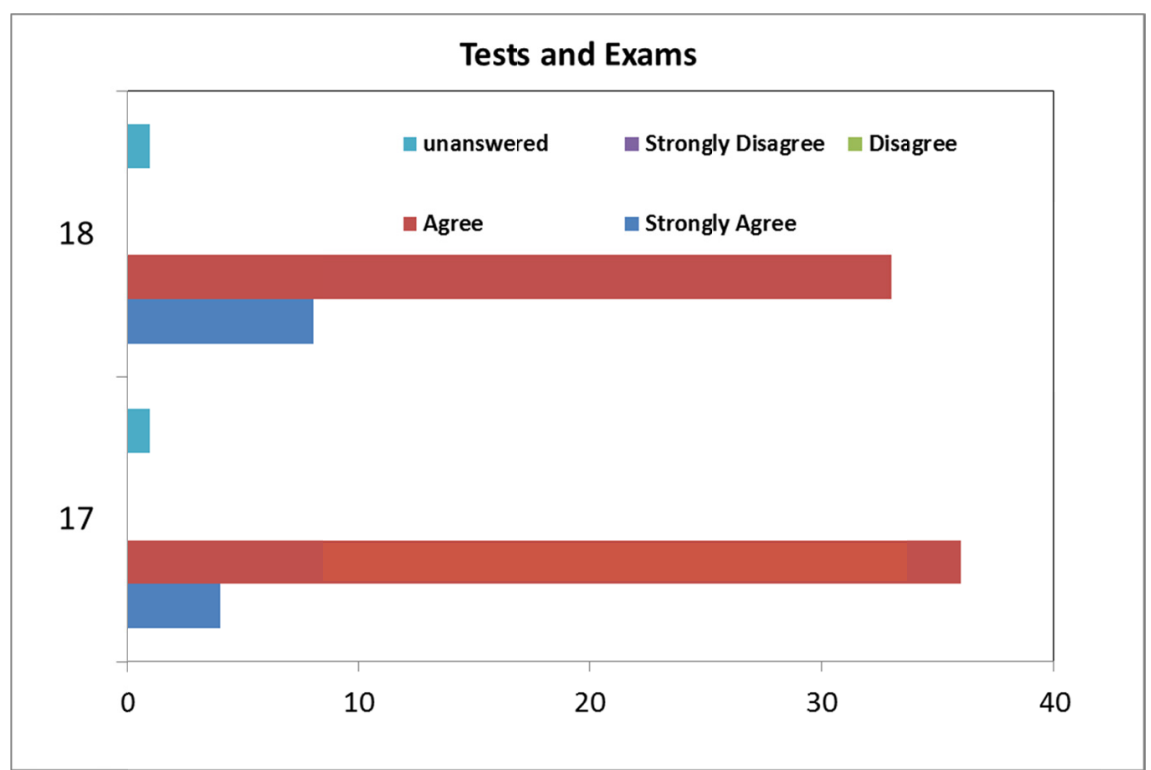

Figure 3d. Students' responses on four questions on assessment (only two choices were chosen)

As far as students are concerned, assessment -- tests and exams -- has an impact on self-evaluation, consolidation of learning and links to the higher-level modules (Figure 3d). In other words, nearing the completion of the module the students go through the process of discernment of the tasks and provide suitable answers (Holland, 2018). This observation suggests that group assignments acts as a powerful lever to collective improvement of learning, through interpersonal and intrapersonal intelligences (Gardner, 2006; Muppala \& Chandramohan, 2019).

Figure $3 \mathrm{~d}$ also shows that the students have given the most satisfactory rating about the impact. In quantitative figures, $85 \%$ students said group learning significantly supporting performance in examinations (Fuller, Kuhne, 
\& Frey, 2011). Moreover, $75 \%$ of them agreed that they are extremely confident and would pass the module with flying colours.

To summarise, through this questionnaire, we made an attempt to understand student learning quantitatively. This study relates students' different learning styles to their learning outcomes. We found that students with comprehension difficulties need additional support, as presented in Figure 1.

Another questionnaire based on an MSc module is discussed below.

\section{Questionnaire - 3:}

The performance of students in both formative and summative test scores was collected in an MSc module Green Engineering (not the complete/actual name in order to anonymise responses) in the year 2018/19. It is a two-week module; with three elements of summative assessments. The formative e-quiz consisted of ten questions (see Appendix B) with test time, with an average 2 mins per question. It was answered by nine students, equivalent of one-fifth of class strength. Brookfield (2017, p. 111) argues that a fifth of a class reflects the opinion of the whole class. We examined the pre-knowledge in three subjects: Fluid Mechanics, Heat Transfer and Mathematics. We picked one assignment [Design of a Solar Energy Collection and Energy Storage System, having $20 \%$ weightage of the total module mark] that requires the knowledge of all these three subjects. This study fulfils the criterion proposed in Caina, Brindley, Brown, Jones, \& Riga, 2019 citing Biesta, 2015:

- Identifies the development of each student as an individual or in groups, "by recognising their unique characteristics and potentials, and by developing their ability to act autonomously and independently."

Analysis of this questionnaire is similar to the one discussed above. This assessment leads the way to identify and offer support in the form of one-to-one discussions, e-support through Canvas to deal with students with very different levels of skills in numeracy and abstraction. For the summative assignment, teaching, for example advanced mathematics and giving basic understanding of underlying physics of fluid flows to students with weaker conceptual skills requires an adaptive approach to teaching in order to improve their learning experiences (Innovation and its contribution to the SoTL, Clark, 2012).

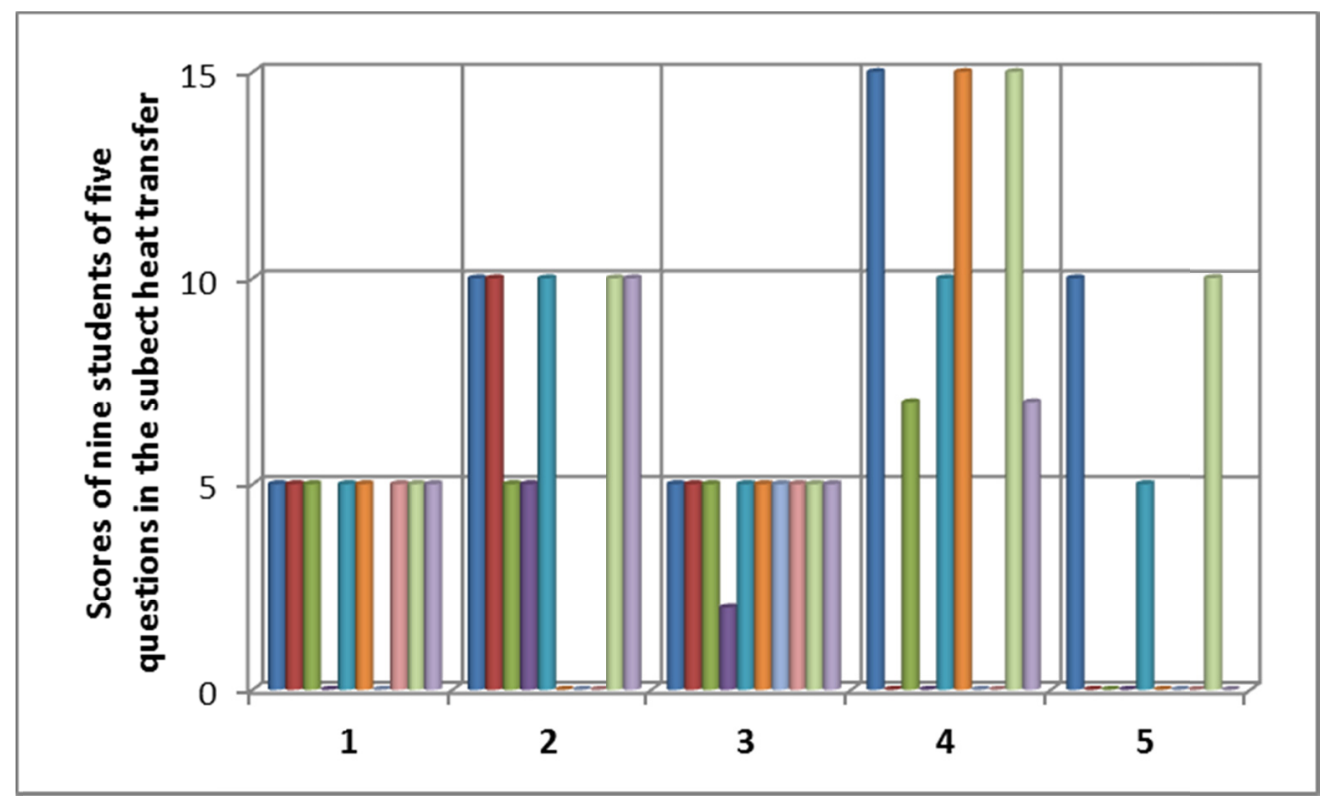

Figure 4a. The marks scored in a pre-knowledge formative assessment test by ten students (each student representing a different colour on bar chart), comprising five questions for 5, 10 and 15 marks, in the subject Heat Transfer

Note. The bar chart represents the number of students who responded against each of the five questions. The y-axis shows scores of nine students to five questions in the subject Heat Transfer.

Figure 4a summarizes scores the pre-knowledge of nine (but ten students responded to Question 3) students out of five questions: two 5-mark, two 10-mark, and one 15-mark questions. Interestingly, the students' levels follow theoretical model proposed by the authors (Figure 2) into three patterns of students' learning levels. 
Jung and Chang (2017) argue creative values in engineering/technology can be applied to empirically explore the fundamental foundation of the inner workings of human beings, such as the importance of the creativity for more-able students, in which MIs interact, and contributions of design thinking. In our study, only three students answered difficult question correctly, the difference between heat and energy. Understanding of this difference means the student has the ability to grasp the underlying physics of thermodynamics laws. Most of them have answered simple questions that have the lowest mark 5, such as 'three modes of heat transfer' and 'the physical proportional quantity in Fourier's law of heat conduction'. More than half of the students have managed to solve an analytical problem that fits into the yellow region in Figure 1. This study once again demonstrates that no two individuals have the same intellectual profile, and those these three students have high logical capacity (mathematical), have linguistic ability to express abstract questions, and can navigate thoroughly the deep concepts. This level of students needs minimal help from the educator.

Questions based on mathematics:

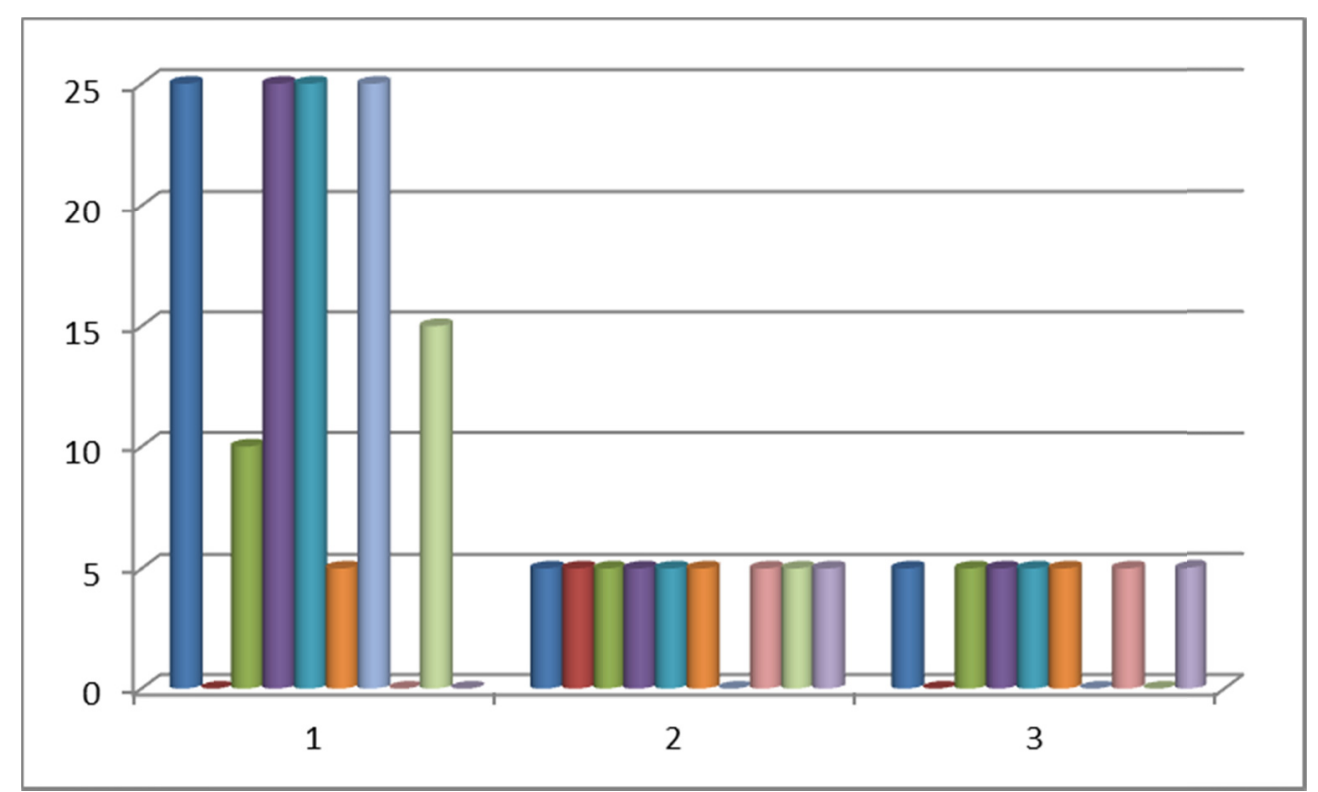

Figure $4 \mathrm{~b}$. The marks scored by ten students in a pre-knowledge formative assessment with three questions, with 5,5 and 25 marks respectively in mathematics

This chart in Figure 4b shows three students have answered all three questions correctly. And, two simple questions, on Trigonometry (and Functions) were answered correctly, respectively, of 8 out of 9 (and 6 out of 9) students for mathematics-based problem, attributed to logical-mathematical intelligence. So, the solving abilities of the students are streamlined with this intelligence. All students are assessed with the same problem but at varied levels to exhibit students with different intellectual profiles (Gardner, p. 56). We use this information to craft the optimal education for each learner. Gardner suggests three entry points, sufficient in individualized education. He sees it as a scientific tool to quantify success and failure.

Figure $4 \mathrm{c}$ shows the measuring parameter - marks that one Fluid Mechanics question- 5 was answered by four students correctly, and five students have scored full marks for question-10. 


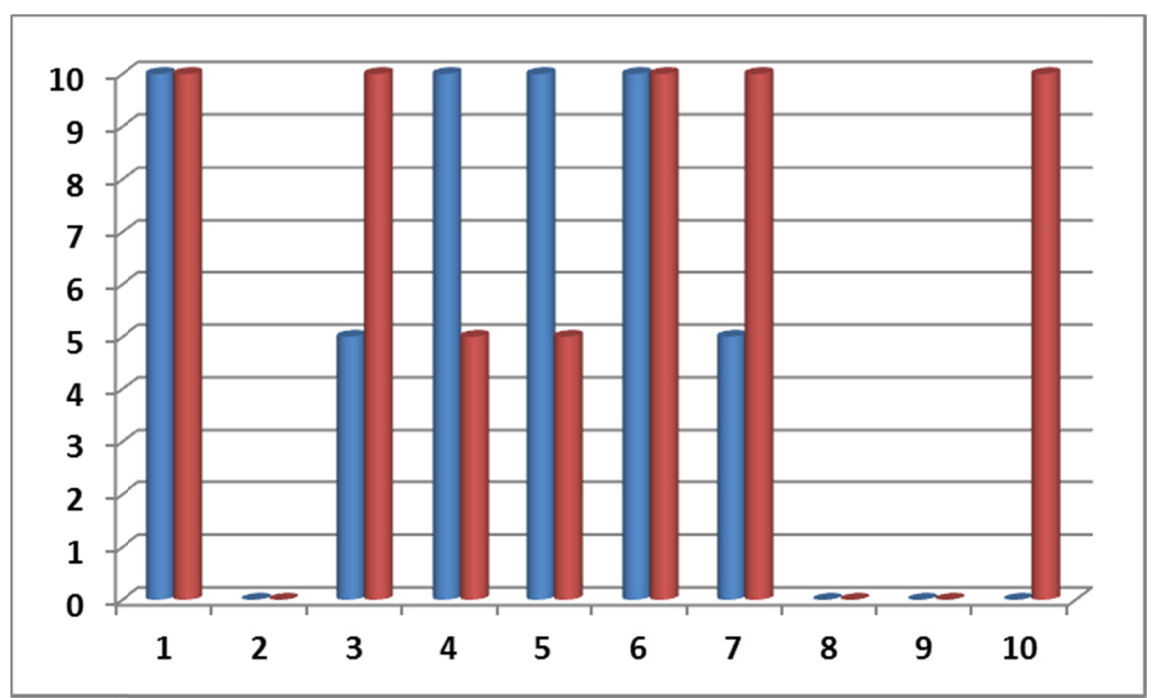

Figure $4 c$. The marks scored by ten students in a pre-knowledge formative assessment with two questions, with 10 marks for each in the subject Fluid Mechanics

See Appendix B for the questions.

In order to handle the above issues, we have put forth three solutions, successfully: challenging questions to more able students, easy to solve problems for students to practice in order to further improve their understanding of the topics and complete solutions for less able students (Elkington, 2017). Gaining this awareness can be of substantial help in redesigning prior perceptions on teaching in student-centred/oriented learning. Moreover, a good alignment of the lectures, Learning Objectives with relevant CATs throughout the functioning of module improves the operation of the module.

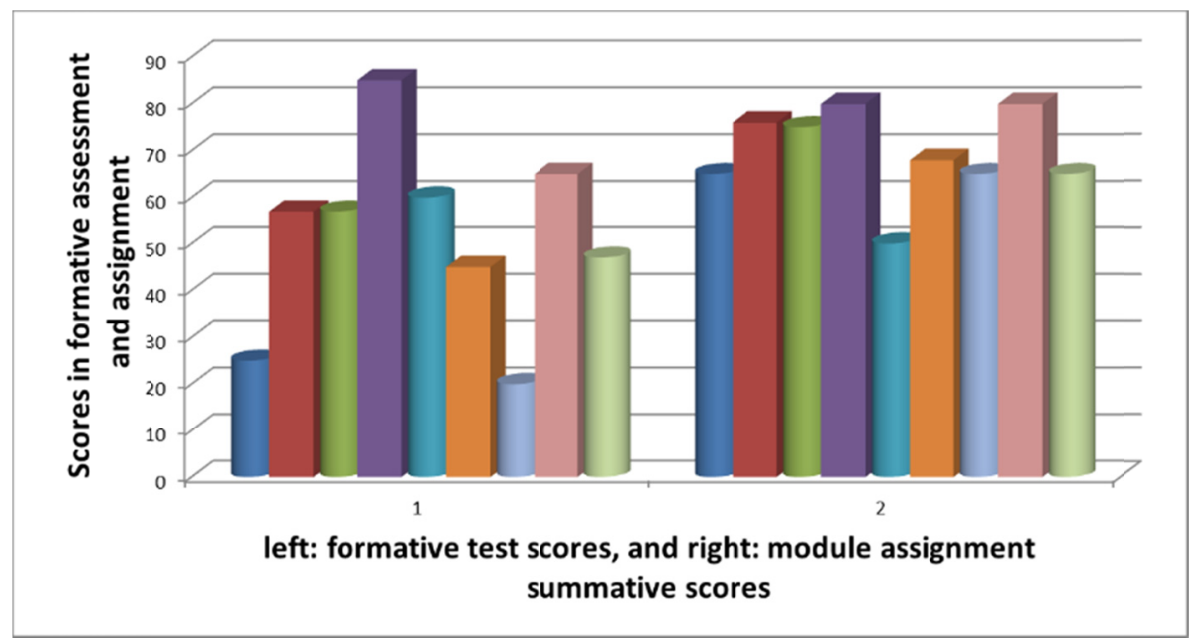

Figure 5. In the present study: comparison of formative assessment scores with an assignment to the advantage of summative score

Figure 5 shows that all the students excepting one student have shown good to very good improvement in their scores in the summative assignment on Solar calculations as compared to their pre-knowledge. We evidence here that in this assignment in which the students conceptualize mathematical equations and solve numerical problems invoke three MIs: logical-mathematical intelligence (problem-solving), linguistic intelligence (e-communication with peers and with instructor) and spatial intelligence (good navigating skills for effective use of Canvas for benefit of learning (Gardner, 2006). 


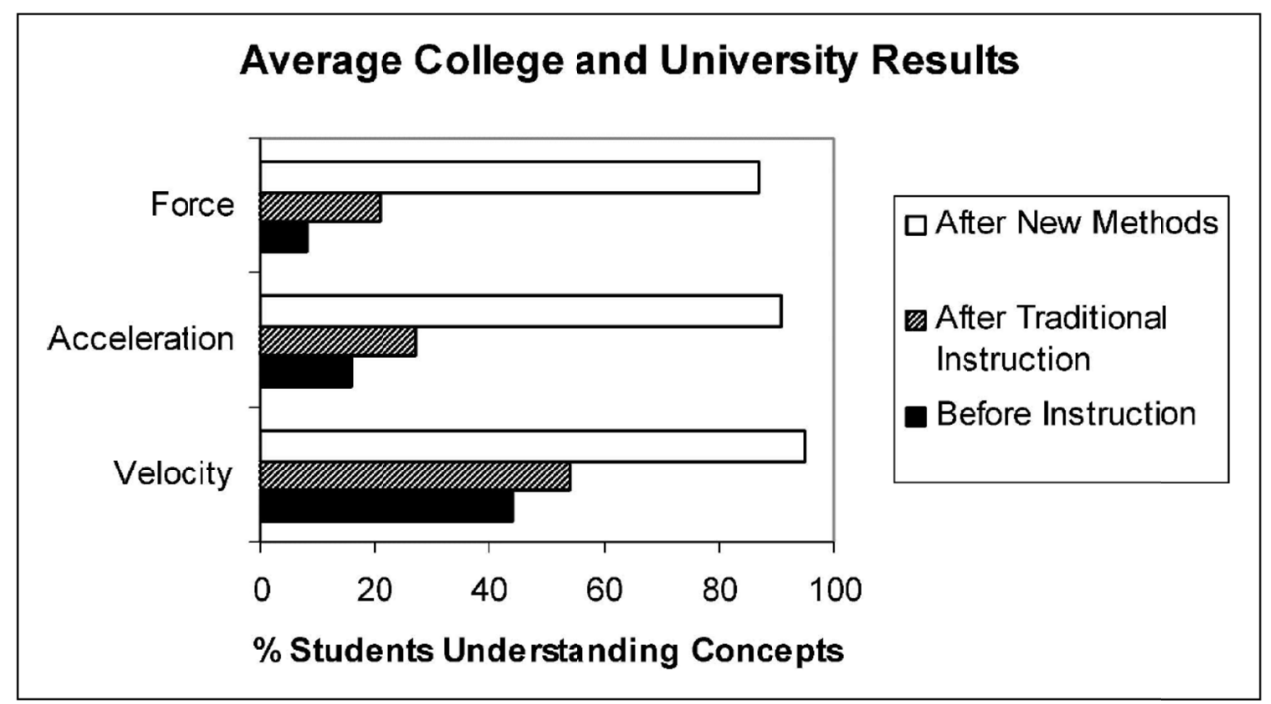

Figure 6. This study shows the benefit of group learning (Prince, 2004 as cited in Laws, Sokoloff, \& Thornton, 1999)

Figure 6 shows positive evidence of group learning using the active learning approach: Prince (2004) as cited in Laws, Sokoloff and Thornton (1999) on page 226.

Laws et al. (1999) opine that in active learning approach, giving two or three pauses in the lecture results in student learning gains, as compared to that in traditional instruction.

Moreover, Jaques (2001) gives positive reasons for combined working helps to support the students in developing responsibility and personal development.

The disadvantage of this active learning is that it is less effective if the difference in the learning levels is high such as in large-class cohorts. It cannot supplant group learning. Because taking short pauses leads to chaos and would be hard to bring back attention/orderliness (Love, Hodge, Grandgenett, \& Swift, 2014).

\section{Maths support:}

The subject of investigation here is to develop innovative methods for students learning. This curve based on a formative assessment helps categorize the students of different level levels/abilities. In this differential concept/approach, the lecturer can offer help to those in need, for example by running additional sessions for maths support (Algozzine, 2007).

A brief maths test was helpful to gauge if there is a requirement for any preliminary equalising studies to support them in first-year studies, in the year 2018 (Figure 7).

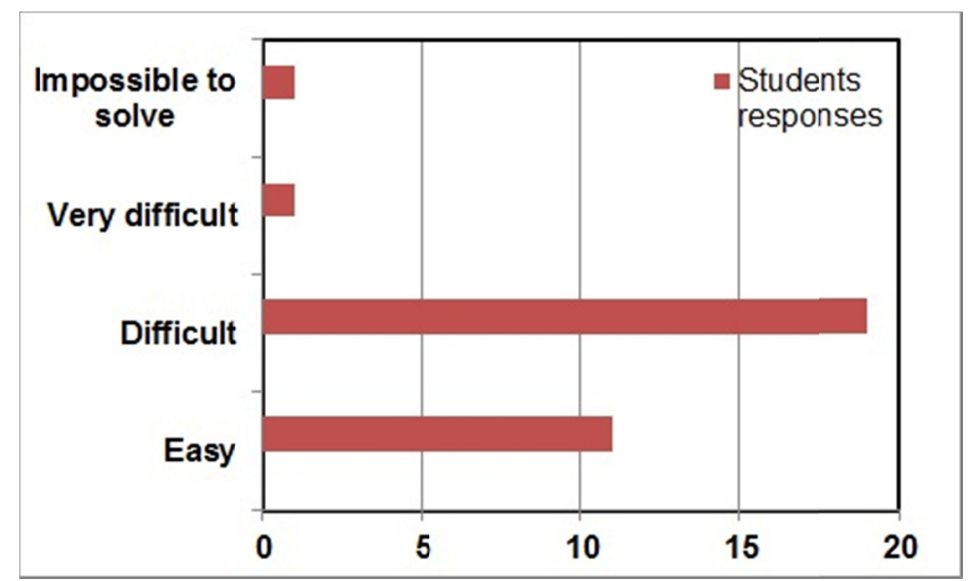

Figure 7. The students' responses were in a formative assessment maths test to assess prior knowledge to ascertain the need for learning support for mathematics 


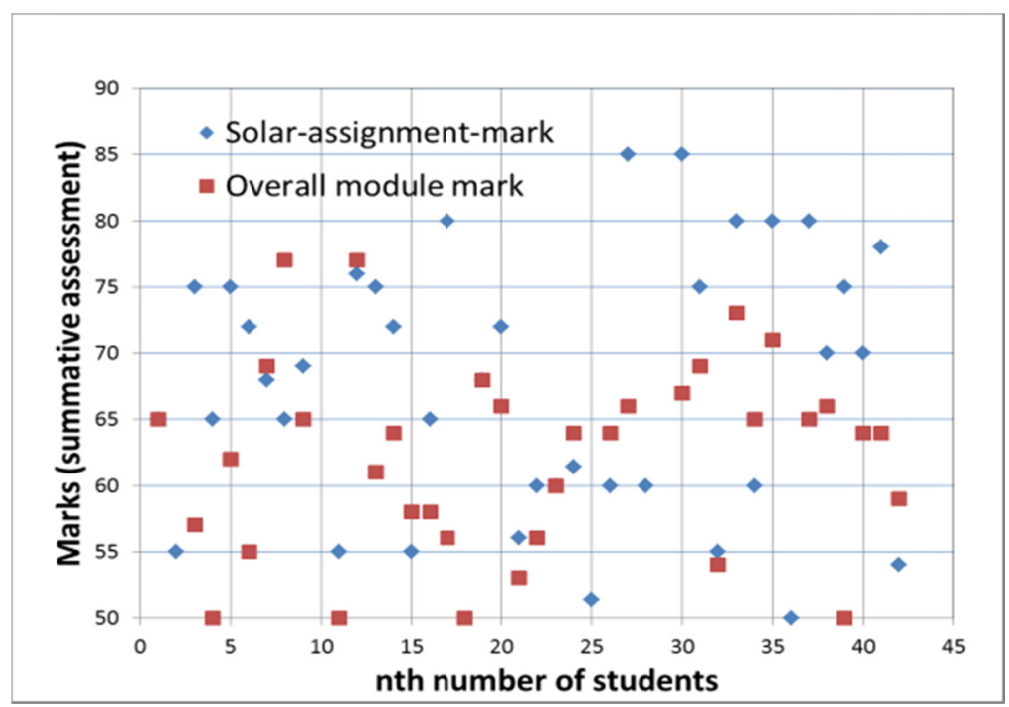

Figure 8. Students' performance-in one of the five assignments conducted in the formative assessment maths test and in the overall mark of the module

This test gives the opportunity to students realize that without the knowledge of engineering mathematics, learning of fluid mechanics cannot go very far. Of forty-two students, 3/4th of them attended support maths session, following their performance in the formative test. Unfortunately, the classroom timetable has not allowed us to conduct a second iteration. However, a porous relation is seen between additional support with the performance in the related summative assignment and the overall mark (Figure 8). Figure 8 shows that all students -- we reckon -- who attended the additional maths session have benefited.

In this way, the students could gain an enhanced ability to creative thinking in solving new engineering problems and successfully build confidence to engage in lifelong learning.

In Engineering disciplines, especially in the problem-solving approach, a range of hands-on curriculum design features and learning technologies can enhance the community aspect of learning. Also, a more inclusive approach to each student type will lead to a greater diversification of student outcomes.

Lewin (1948) in the study on integrating social science subjects noted that "integrated approach" of various disciplines gave expected benefits of improving learning. In other words, progress will depend largely on students' learning if mathematics is embedded across the curriculum. Therefore, this approach was adopted based on students' needs, and similar lectures are envisaged. Moreover, evaluation gives an opportunity to reflect on our additional efforts to benefit the students and possibly revisit the curriculum contents.

This finding ascertains the need for additional learning support for mathematics. As a result, seventeen students attended a lecture. Figure 8 shows student responses of a quiz and of these 13 students attended the extra support lecture. It was not possible to quantify how/how much this additional support has explicitly helped them in the overall performance in the module.

\section{Conclusions}

In this study, we have used an innovative approach to enhance students' learning in a classroom. In developing our approach, we systematically evaluated three questionnaires designed for students, one each on first- and second-year undergraduate courses, and the third on a Post graduate course. These courses are unrelated to each other (i.e., no pre-requisite modules were needed to progress).

We found that the students' learning abilities follow a pattern in line with our theoretical model and that weak students need more teacher support, e-support (such as photocopy of handwritten notes, posters etc.) and group learning.

To summarize our work, we demonstrate that learning in a classroom is dynamic in nature and that there are significant benefits of using Multiple Intelligences to support students with different learning levels and abilities. We also stress the need to increase variation in teaching so that all students learn well and graduate with high self-esteem and become independent learners. 
Anticipated impact: Our study can help teaching staff to address an important task, to ensure that s/he is able to monitor and measure the students' progress and achievement in engineering subjects. We hope this approach can be applied to other disciplines too, and that the staff can take a more active/differentiated role and adopt these approaches to enhance their students' classroom learning, especially of the weaker students.

Further research: Following this study, we propose to carry out further investigations during the Academic Year 2020-2021 to cover additional variables related to educational and social experience of diverse groups of students. We hope that our findings could help to develop new interventions (or make adjustments to current classroom practice) at Kingston University and beyond and enrich and enhance student experience of learning.

\section{References}

Algozzine, B., \& Anderson, K. M. (2007). Tips for Teaching: Differentiating Instruction to Include All Students. Preventing School Failure: Alternative Education for Children and Youth, 51(3), 49-54. https://doi.org/10.3200/PSFL.51.3.49-54

Barrington, E. (2007). Teaching to student diversity in higher education: how Multiple Intelligence Theory can help. Teaching in Higher Education; Critical Perspectives, 421-434. https://doi.org/10.1080/1356251042000252363

Biesta, G. (2015). On the two cultures of educational research, and how we might move ahead: Reconsidering the ontology, axiology and praxeology of education. European Educational Research Journal, 14(1), 11-22. https://doi.org/10.1177/1474904114565162

Brookfield, S. D. (207). Becoming a Critically Reflective Teacher (2nd ed.). JOSSEY-BASS, A Wiley Brand.

Caina, T., Brindley, S., Brown, C., Jones, G., \& Riga, F. (2019). Bounded decision-making, teachers' reflection and organisational learning: How research can inform teachers and teaching. British Educational Research Journal, 45(5). https://doi.org/10.1002/berj.3551

Cerbin, B. (2013). Emphasizing Learning in the Scholarship of Teaching and Learning. International Journal for the Scholarship of Teaching and Learning, 7(1). https://doi.org/10.20429/ijsotl.2013.070105

Clark, E., \& Webster, B. (2012). Innovation and its contribution to the scholarship of learning and teaching. Nurse Education Today, 32, 729-731. https://doi.org/10.1016/j.nedt.2012.06.001

Dirksen, J. (2016). Design for how people learn (2nd ed.). Pearson Education.

Elkington, S. E. C. (2017). Transforming Assessment in Higher Education: A Case Study Series.

Fuller, R. G., \& Kuhne, G. W. (2008). Fostering Meaningful Interaction in Health Education Online courses; Matching Pedagogy to course types. International Journal of Communication Technology Education, 4(1). https://doi.org/10.4018/jicte.2008010105

Fuller, R. G., Kuhne, G. W., \& Frey B. A. (2011). Distinctive Distance Education Design: Models for Differentiated Instruction ( p. 21). Book publisher Information Science Reference, IGI Global.

Gardner, H. (2006). Multiple Intelligences: New Horizons (pp. 8-18). New York: Published by Basic books, a member of Perseus Books Group.

Gargiulo, R. A., \& Metcaf, D. (2016). Teaching in Today's Inclusive Classrooms: A Universal Design for Learning Approach (3rd ed.). Wadsworth Publishing.

González-Marcos, A., Alba-Elías, F., Navaridas-Nalda, F., \& Ordieres-Meréc, J. (2016). Student evaluation of a virtual experience for project management learning: An empirical study for learning improvement. Computers \& Education, 102, 172-187. https://doi.org/10.1016/j.compedu.2016.08.005

Holland, E. P. (2018). Making sense of module feedback: accounting for individual behaviours in student evaluations of teaching. Assessment \& Evaluation in Higher Education, 44, 961-972. https://doi.org/10.1080/02602938.2018.1556777

Hutchings, P. B., Keesing-Styles, L., Martin, L., Michael, R., Scharff, L., Simkins, S., \& Ismail, A. (2013). The Scholarship of Teaching and Learning in an Age of Accountability: Building Bridges. Teaching \& Learning Inquiry: The ISSOTL Journal, 1(2), 35-47. https://doi.org/10.20343/teachlearninqu.1.2.35

Jaques, D. (2001). Learning in Groups: A Handbook for Improving Group Work. Journal of European Industrial Training, 25(1), 3/e. https://doi.org/10.1108/jeit.2001.00325aae.001

Jung, J., \& Chang, D. (2017). Types of creativity—Fostering multiple intelligences in design convergence talents. Thinking Skills and Creativity, 23, 101-111. https://doi.org/10.1016/j.tsc.2016.12.001 
Laws, P., Sokoloff, D., \& Thornton, R. (1999). Promoting active-learning using the results of Physics Education Research. Uniserve Sciences News, 13.

Lei, Y. (2005). Using problem based learning in Electrical Engineering Foundation. The China Papers, 5, $67-70$.

Lewin, K. (1948). Action research and minority problems. In G. W. Lewin (Ed.), Resolving Social Conflict. New York: Harper \& Row publishers.

Lock, G. (2007). Fluid Mechanics with Historical Perspective. Journal of the Higher Education Academy (Engineering Subject Centre), 1(2), 33-39. https://doi.org/10.11120/ened.2007.02010033

Love, B., Hodge, A., Grandgenett, N., \& Swift, A. W. (2014). Student learning and perceptions in a flipped linear algebra course. International Journal of Mathematical Education in Science and Technology, 45(3), 317-324. https://doi.org/10.1080/0020739X.2013.822582

Matrisciano, A. B., \& Bilfore, N. P. (2010). An investigation on Cognitive Styles and Multiple Intelligences Model based Learning Preferences in a group of students in Engineering (pp. 60-66). In International Conference on Information Technology Based Higher Education and Training, IEEE. https://doi.org/10.1109/ITHET.2010.5480063

McCarthy, M., Neville, G., Higgs, B., \& Murphy, J. (2010). From dry ice to Plutarch's fire: The integration of research and teaching and learning. Medical Education: The State of the Art.

Muppala, S. P. R., \& Chandramohan, B. (2017). Problem Based Learning. AdvanceHE.

Muppala, S. P. R., \& Chandramohan. B. (2019). A quantative approach to Problem-Based-Learning based on a Questionnaite: A model for student learning outcomes (a case study). In 3rd EuroSoTL Conference. Bilbao, Basque Country.

Newman, T. B., \& Knight, S. (2018). Digital experience insights survey 2018: findings from students in UK further and higher education. Retrieved from https://www.jisc.ac.uk/

Norman, G., \& Schmidt, H. (2000). Effective of problem-based learning Curricula: Theory, Practice and Paper Darts. Medical Education, 34, 721-728. https://doi.org/10.1046/j.1365-2923.2000.00749.x

Plsek. (1999). Innovative thinking for the improvement of medical systems. Annals of Internal Medicine, 131(6), 438-444. https://doi.org/10.7326/0003-4819-131-6-199909210-00009

Prince, M. (2004). Does Active Learning Work? A review of the research. J. of Engr. Education, 93(3), 223-231. https://doi.org/10.1002/j.2168-9830.2004.tb00809.x

QAA. (2018). THE UK QUALITY CODE for higher education.

Ramsden, P. (1992). Learning to Teach in Higher Education (p. 290).

\section{Appendix A}

\section{Level -4 course}

In this formative test, all students are given the task, to work in groups or individually, of their choice. Groups are formed by students themselves randomly. Description of the problem: Figure A1. Shows a set up with an air-filled vertical cylinder fitted with a frictionless piston and a set of breaks. It is assumed that air will behave as a thermally perfect gas. The piston's cross-sectional area is $0.4 \mathrm{~m}^{2}$ and the air inside is initially at $200 \mathrm{kPa}$ and $533^{\circ} \mathrm{C}$. The air is then slowly cooled as a result of heat transfer to the surroundings. 


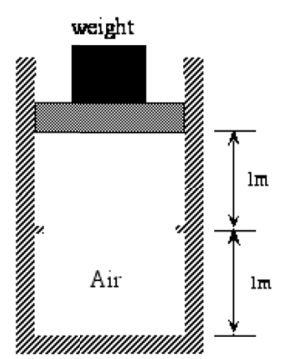

Figure A1

This Figure A1 depicts piston-cylinder assembly with the fluid (air) in the system and the dimensions of the cylinder.

Tasks:

a) Identify the number of processes and sketch them as p-v and T-v diagrams.

b) Estimate of air temperature of the air inside the cylinder when the piston reaches the stops?

c) Estimate pressure when temperature reaches $25^{\circ} \mathrm{C}$.

d) Work done by the system in the first and second cooling processes?

Please follow standard sign conventions for work and energy on and to the system.

The student performance is given in Figure1 in the main body text.

\section{Appendix B}

Questionnaire in MSc module (Level - 7) with the subject heading:

Solar Air Heaters: It contains ten questions in the order: Heat transfer (HT) and mathematics (M). Fluid Mechanics (FM)

QHT1. What is the quantity that originates in Fourier's law of heat conduction?

QHT2. What is the significance of heat transfer coefficient?

QHT3. What are the three modes of heat transfer?

QHT4. From the thermodynamic point of view, what is the difference between heat and energy?

QHT5. If density of gas at $25^{\circ} \mathrm{C}$ is $1.8 \mathrm{~kg} / \mathrm{m}^{3}, \& 75^{\circ} \mathrm{C}$ is $2.4 \mathrm{~kg} / \mathrm{m}^{3}$, what is it at $30^{\circ} \mathrm{C}$ ?

$\mathrm{QM} 1$. For an equation $\mathrm{z}=\mathrm{f}(\mathrm{x}, \mathrm{y})$, where $\mathrm{x} \& \mathrm{y}$ are two independent variables, write this equation in differential form

$\mathrm{QM} 2$. If $\tan$ (theta) $=1$ and $\sin$ (theta) $=0.5$, what is $\cos$ (theta) ?

$\mathrm{QM} 3$. What does this equation mean $\mathrm{T}=\mathrm{f}(\mathrm{x})$ ? where $\mathrm{T}$ is temperature and $\mathrm{x}$ is a distance.

QFM1. What is a steady flow?

QFM2. What is a fluid?

The results are shown in chapter Questionnaire - 3: Figures 4a, 4b, and 4c.

\section{Copyrights}

Copyright for this article is retained by the authors, with first publication rights granted to the journal.

This is an open-access article distributed under the terms and conditions of the Creative Commons Attribution license (http://creativecommons.org/licenses/by/4.0/). 